\title{
Roundtable: Revisiting Innovative Leaders in Medical Education
}

\author{
André-Jacques Neusy MD DTM\&H and Bjorg Palsdottir MPA
}

In the fall of 2008, MEDICC Review published a roundtable discussion with six of eight deans representing schools of health sciences with a strong social accountability mandate, who had just founded a new collaborative: the Training for Health Equity Network (THEnet). The topic was the changing paradigm of medical education. MEDICC Review returns to hear their perspectives on how their schools contribute to universal coverage, the theme of this issue.

An appropriate health workforce is a critical component of universal health coverage. Discussions until now have focused mostly on managing supply and demand. Yet, it has become increasingly clear that what is needed is a fundamental shift in approach: different types of health workers employed in different ways in different health systems to meet the needs of all.

Because the traditional "ivory tower" model of medical education is failing to meet the health and social needs of the underserved, THEnet schools are pioneering innovative models to improve access to and quality of health services in disadvantaged communities. Through THEnet, voices of the underserved are being heard-challenging the policies, institutions, and orthodoxies that have systematically failed these populations.

THEnet schools measure their success, not by how many graduates they produce or how many of their articles have been published, but by whether their graduates have the right competencies to meet the needs of their reference populations and whether a large proportion of them stay and work in regions where they are most needed. They also measure whether their research and services positively affect health policies and practice and improve health in vulnerable communities.

MEDICC Review: WHO defines social accountability of medical schools as the obligation to orient teaching, research and service activities to addressing the priority health needs of the communities they have a mandate to serve, defining those needs in collaboration with government, health service organizations, health professionals and the public.[1] How does this contribute to making universal health coverage possible?

Paul Worley (Flinders): The best health policies are of limited value if there are insufficient numbers and quality of clinicians to put them into practice. Socially accountable medical education must produce adequate numbers of graduates who are willing to work in the areas of most need. It must also produce graduates who are of a quality that will provide the high level of service and expertise that our communities deserve. The process of this education should also contribute to the social and intellectual capital of the regions concerned.

Khaya Mfenyana (WSU): Socially accountable medical education contributes to universal health coverage because teaching is based on the health needs of the country; and because of the strong partnership between the university, the department of health, policy
Community engagement is hardwired into the schools' activities, a cornerstone of their mission to impact health service provision and health workforce retention in disadvantaged areas. THEnet schools view the public as a vital component of the health system, and of any effort to expand health coverage. In their experience, communities can be mobilized and supported to take responsibility for their own health and promote health-seeking behavior, becoming partners in developing solutions to their health challenges.

THEnet is scaling up its research and capacity development activities to examine the return on investment in communityengaged socially accountable education, and to better support schools through evidence-based strategies, peer learning environments, and practical tools. The aim is to demonstrate that health equity is a realistic and actionable goal for sustainable health workforce development.

The deans interviewed for this roundtable are: Dr Juan Carrizo, Rector of the Latin American Medical School (ELAM), Cuba; Dr Fortunato L. Cristobal, founding Dean of the School of Medicine at Ateneo de Zamboanga University (ADZU), the Philippines; Dr Khaya Mfenyana Executive Dean, Faculty of Health Sciences, Walter Sisulu University (WSU), South Africa; Dr Richard Murray, Dean and Head of the School of Medicine and Dentistry, James Cook University (JCU), Australia; Jusie L.J. Siega-Sur, Dean, University of the Philippines Manila-School of Health Sciences (SHS); Dr Roger Strasser, founding Dean of the Northern Ontario School of Medicine (NOSM), Canada; and Dr Paul Worley, Dean of Flinders University School of Medicine (FUSM), Australia. makers, health service managers, health service providers and communities themselves. Socially accountable medical education therefore produces not just more doctors, but doctors able to address the needs of all people of a particular country, especially the poor and underserved.

Richard Murray (JCU): Although universal health care is theoretically available in Australia, problems with accessibility and acceptability of services really limit this for many rural, remote and indigenous Australians. Through our training, we aim to produce graduates who really want to make a difference in these areas. Furthermore, they will have appropriate competencies to allow them to practice effectively and safely in rural, remote and indigenous settings, including skills in cross-cultural communication and practice, and appropriate clinical skills.

MEDICC Review: What do you consider your school's main contribution to expanding access to health care for marginalized populations?

Jusie L.J. Siega-Sur (SHS): Long before the WHO recommendations on rural retention, our school recruited scholars from impoverished rural communities, trained them in areas similar to their future 
practice settings, equipped them with relevant competencies, and provided them with scholarships. These are key factors in retention of graduates serving in underserved and marginalized areas of the country. More than 20 years later, $90 \%$ of our medical graduates continue to serve in the country, mostly in the public health sector and the community.

The school also pioneered a community and competency-based stepladder program that integrates training of midwives, nurses and physicians in a single, sequential, and continuous curriculum. A student enters the program at the midwifery level. Based on several criteria, including community need and endorsement, a student may progress through the various levels of the curriculum. Graduates are required to render return service in underserved communities after completion of each level. A key innovation was community participation in student recruitment and evaluation.

Our school has been a breeding ground for innovating and testing new strategies in health sciences education in the country and SHS faculty participated in the crafting of the WHO document on community-based education. The program as a whole and some of its components have been replicated in other areas of the Philippines and abroad.

The school's research and development program in the early years contributed to the re-structuring of the country's health care delivery system with the adoption of a catchment area system to delineate areas of health service coverage;

Khaya Mfenyana (WSU): WSU has expanded access to health care to marginalized populations by establishing four Academic Health Care Centers in a region previously without decent health facilities. Now communities have access to health care closer to where they live. By sending students and faculty to district hospitals and their surrounding communities in Eastern Cape Province of South Africa, WSU increases sorely needed manpower in underserved communities, and has also managed to improve drug and medical equipment supply.

The experience of the medical program also gave rise to a Clinical Associate (Physician Assistant) Program, almost completely community-based from inception. At the end of 2010, WSU graduated the first cohort of Clinical Associates (23) in the history of South Africa. These health professionals received over $90 \%$ of their training in district hospitals and community health centers in the Eastern Cape. As of January 2011, all of them are working at district hospitals where there is a great shortage of doctors.

Lessons learned from WSU's medical program are being applied in other parts of Africa including Botswana, Zimbabwe, Ghana and Ethiopia.

Paul Worley (Flinders): Our school's main contribution has been to demonstrate the academic excellence and career outcomes of enabling medical students to learn for extended periods of time in marginalized rural communities with generalists as mentors and supervisors. This has given confidence to many schools to move to this approach without having to compromise their commitment to quality outcomes.

Juan Carrizo (ELAM): I believe we are helping to create a "critical mass" of physicians of a new kind, throughout the developing world in particular, who believe in the right to health care, have a quality education that melds clinical medicine with public health, and who are willing to practice in shortage areas and confront the obstacles along the way.

Roger Strasser (NOSM): NOSM enhances universal health coverage as its students add capacity to the health team in clinical learning sites located in rural communities of Northern Ontario. Its program has improved recruitment and retention of health professionals in the region, and increased the number of graduating health professionals with the skills and inclination to practice in Northern Ontario or similar rural underserved areas.

NOSM provides a model of socially accountable medical education for other medical schools in Canada and around the world. In this sense, NOSM's membership in THEnet is a key component: for example, through THEnet, NOSM has assisted with medical education developments in Ethiopia and other African countries.

Richard Murray (JCU): Having graduated only five cohorts of students, it is still early days. However, the school has made a significant contribution to the medical workforce in north Queensland, with many graduates choosing to practice in rural and remote areas: we have doubled the resident medical officer workforce in the region.

Furthermore, our school has graduated 10 indigenous doctors to date, and another 20 indigenous medical students are enrolled. This has the dual effect of increasing accessibility of health services to Aboriginal and Torres Strait Islanders generally, but also increasing the visibility of medicine as a possible career choice to communities who previously did not consider it.

Some of our doctors are now contributing by teaching in our program. Academics from our school have also been instrumental in working towards a variety of post-graduate training pathways that will meet the health needs of underserved populations, namely the Rural Generalist Training Program and the Northern Clinical Training Network, both in partnership with Queensland Health Department, the regional health authorities.

Cristobal Fortunato (ADZU): We have improved health care indices: in the 1980s and 1990s before the creation of ADZU, infant mortality in the region was around 80 per 1000 live births. Now it is 8 . We have graduates in the Zamboanga Peninsula, Sulu, Basilan, and Tawi-Tawi Islands. These graduates serve hundreds of thousands of patients who otherwise would not have access to health care in isolated, conflict-ridden and depressed areas. Our graduates have won awards from the national government for excellence in the "Doctors to the Barrios" program.

MEDICC Review: How many physicians has your school graduated? Do you follow up with students after graduation? If so, in what settings are most practicing now?

Jusie L.J. Siega-Sur (SHS): The health care system of the Philippines places the midwife as the frontline worker and the school has graduated more than 1400 midwives since 1984. It has also graduated over 650 nurses and 125 physicians.

The school has tracked all of its medical graduates. The majority of licensed graduates practice in disadvantaged and underserved areas of the country in roles such as municipal or provincial health officers and independent community practitioners. Less than $10 \%$ 
have migrated abroad after serving in the community for an average of 15 years. A good number have also pursued residency training in internal medicine, surgery, pediatrics, obstetrics, anesthesia, and other specialties. After completing residency training, these practitioners have gone back to serve in district and provincial hospitals in the areas where they come from.

Juan Carrizo (ELAM): We have graduated 8594 since the first class in 2005-students from 58 countries throughout the developing world and the USA. Just in the last year have we been able to establish institutional follow-up, which aims to track and network with graduates, as well as provide them services. We expect concrete results by this time next year, since you can imagine that locating and communicating with all these graduates is not easy.

Yet, we already know that many are practicing in rural and remote areas; others are specializing here in Cuba or in their home countries; some are taking state exams for licensing; and still others are unemployed. The last category is especially troubling to us: it represents the inability of some public health systems to absorb these wonderful new doctors, because of budgetary constraints imposed during the neoliberal "health reform era"; and in other cases represents resistance by local medical societies to accept graduates from a different kind of medical school-however good the academic training may be. It is ironic, for example, that we have graduates who have passed their exams and are in residency programs in the United States; but in a few other countries, their degrees are still not recognized. Today, thankfully, these countries are few.

Khaya Mfenyana (WSU): WSU is situated in the mainly rural Eastern Cape Province of South Africa, one of the poorest provinces in this country. The school has graduated 1012 physicians over a period of 20 years; $72 \%$ of our graduates are working in the underserved areas of the Eastern Cape and KwaZulu-Natal Provinces, from where most of our students originate. Those who practice in urban and peri-urban areas include interns and doctors in postgraduate training at tertiary hospitals, and those in private practice in the former black townships.

Paul Worley (Flinders): Our first class of 64 students graduated in 1980. We have grown, and now are enrolling over 150 new students each year. Our graduates are working across all medical specialties and locations. More recently, with an increased focus on recruiting students from underserved areas and training them in small rural and remote communities, the majority of our graduates are choosing to practice in underserved areas.

In particular, we have just commenced recruiting students from the remote Northern Territory to undertake their entire medical course based in the Territory. Of the 24 students who entered in February 2011, 10 identified as aboriginal Australians. Along with 4 aboriginal students in our southern campus, this cohort will increase by $10 \%$ of the number of indigenous doctors currently practicing in the whole of Australia. We anticipate similar numbers in our next cohort as well. Together, these students represent an opportunity to transform our country's approach to closing the gap of indigenous health disadvantage.

Roger Strasser (NOSM): NOSM, in operation since 2002, has graduated 2 classes from the MD program, a total of 107 graduates. The NOSM Tracking Study surveys all students and graduates every 2 years, finding that $65 \%$ of our graduates are in predominantly rural family medicine residency programs and almost all of the other $35 \%$ are training in other general specialties suitable for rural practice. Many of the family medicine residents have signed contracts to practice in Northern Ontario or other rural areas.

Richard Murray (JCU): Over 6 years, JCU has produced 450 graduates. We follow them with a regular graduate outcome survey, applied at graduation and then at 5-year intervals, and also track location annually. Most are working in outer regional, rural and remote settings, and are largely pursuing careers as general practitioners, rural procedural practitioners, in generalist specialties and in public health. Of the graduates to date, $45 \%$ have undertaken their internship (first postgraduate year) in outer regional or remote locations, $20 \%$ in inner regional locations and 35\% in major cities. This pattern has persisted into later postgraduate years. There has been a significant association between rurality of home address and rurality of practice after graduation but around half the cityorigin students also choose regional locations.

Cristobal Fortunato (ADZU): We have a total of 271 graduates from 16 years of operation. Of those, 79 are in required post-graduate internships, preparing for board exams or have just passed them. Our retention rate within the Philippines is $97.2 \%$ and $79 \%$ have stayed in conflict-ridden Zamboanga Archipelago and the Autonomous Region in Muslim Mindanao. About $66 \%$ of graduates are employed by the government; $48 \%$ work in rural and remote areas.

\section{MEDICC Review: Are you satisfied with the contribution your graduates are making to expanded health coverage to under- served populations?}

Jusie L.J. Siega-Sur (SHS): In general, the school is proud of what its graduates have accomplished. In the end, the school's success will be measured by the number of graduates serving in areas of most need and the quality of service they provide. Thus far, these goals have been achieved through high retention rates and the types and quality of service rendered by our graduates. Their contributions to addressing health inequities in the country have ranged from direct care to improvement in the management and delivery of health services, and policy development.

The school has been acclaimed for its high retention rates as well as for its pioneering work in the step-ladder curriculum and development of community-oriented health practitioners. It was awarded the Presidential Lingkod Bayan Award, the highest award for service to the nation.

We are planning new initiatives to support our graduates. These include continuing education programs and innovative programs enabling community practitioners to earn a master's degree in public health, while at the same time doing a residency in family medicine. Those working in hospitals will be able to earn a master's degree in hospital administration and do a residency in family medicine.

Khaya Mfenyana (WSU): I am satisfied with the contribution of our graduates in expanding health coverage to marginalized communities. Even those in urban or peri-urban areas who engage in private practice work mostly in underserved former black townships. In partnership with the Eastern Cape Province, the University is planning to introduce a social compact for students who receive bursaries. This will involve the community more intensively in selection of students for bursaries and, in turn, students will sign contracts to serve these communities after completion of their studies for an number of years equal to their bursaries. 
Roger Strasser (NOSM): It is too early to draw firm conclusions; however, the signs are promising that NOSM graduates will make a substantial contribution to expanding health coverage to underserved populations. Already, a study of the socioeconomic impact of NOSM has shown that the School has contributed to improved recruitment and retention of physicians and other health professionals in Northern Ontario, and has had considerable socio-economic impact.

Richard Murray (JCU): Although there is always more that we could do, we have been quite satisfied with the distribution of practice location and fields of practice that our graduates have chosen to date. Furthermore, they are getting excellent feedback from their employers within the health sector about their workreadiness and clinical skills. While confident that they are making a great contribution, we are also working to strengthen teaching of research and public health skills, leadership, and advocacy in the curriculum.

Cristobal Fortunato (ADZU): We have provided physicians to many rural areas, but to say that we are satisfied is incorrect. Manpower is essential and we are definitely having an impact on health services, local health policies, and community health outcomes. But we must sustain the quality of our alumni. We have initiated a critical care course for rural practitioners in the last three years, improving the emergency care capabilities of our graduates.

This year, we expanded that program into a Rural and Remote Area Medicine Course that included material other than critical care. We have been running the third largest course for rural physicians in the world today. We have also collaborated with Humanitarian Emergency Logistic and Preparedness, (HELP) to provide several million pesos worth of equipment to rural clinics and we are working on a grant to support graduates through Continuing Medical Education and e-health initiatives, including the use of mobile phone technology.

Juan Carrizo (ELAM): We are pleased, but not yet satisfied. We are pleased because we have seen the social commitment and quality of our graduates' work in many countries, particularly in the communities that need them most. And we are especially proud of their involvement in Haiti after the 2010 earthquake-hundreds volunteered, and finally we had to choose among them. Today, 163 are still in Haiti-including a large number of our Haitian graduates-working alongside the Cuban medical team and many completing their residency in family medicine there as well. They are providing services free to the population and, most importantly, helping to build a health system that will reach all Haitians.

At the same time, we would like to see more comprehension on the part of medical societies in some countries, enabling them to welcome these graduates and smooth their way towards licensing, rather than viewing them as competition as sometimes happens.

\section{MEDICC Review: In your experience, what non-financial factors foster health professionals' long-term commitment to practice in communities that have had little or no access to health care?}

Jusie L.J. Siega-Sur (SHS): Based on initial results of a study on best practices, we have identified several factors in our setting that contribute to long-term retention of graduates where they are most needed. The first set includes factors related to the program, such as recruitment of students of rural and disadvantaged origins; a strong orientation towards community service; a longitudinal and prolonged community immersion; knowledge and competencies appropriate to community needs and practice settings of graduates; and a social contract between the students and the community to render return service. Also important have been the policy on return service obligation; providing scholarships; familiarizing students prior to enrollment with the school's mandate and their obligations after completion of the program.

Second are community-related factors, including support and partnership with communities in the training of scholars and deployment of graduates; partnership with stakeholders, especially the Department of Health and target communities; availability of positions in local government units and in district and provincial hospitals in graduates' home areas; and positive role models in the community.

Third are the individual factors, such as students' innate willingness to stay and serve the community; presence of family and friends and other support systems in the community; personal satisfaction derived from serving in the community; and the perceived adequacy of resources to support lifestyle and family needs.

Paul Worley (Flinders): Three aspects are key: first, selecting students from these environments brings an innate empathy and likelihood of return. Second, teaching significant parts of the course, or the whole course, in marginalized communities not only equips students to work in these environments but also sends a message about the University's priorities for these communities and helps provide support for clinicians working there. Third, it is important to ensure that students have time, through long-term clinical attachments, to get to know dedicated clinicians who work successfully in such environments and can provide the mentorship and inspiration to foster commitment from students and young graduates.

Roger Strasser (NOSM): Community engagement is a key factor. Health professionals who feel they are valued and respected members of the community are much more likely to make a long-term commitment. This is even more likely if the health professional grew up in that community. Academic involvement (teaching and research) is also a strong motivator for recruitment and retention of health professionals in rural underserved areas.

Cristobal Fortunato (ADZU): Success breeds commitment even more than money. In our experience, graduates who are able to make a visible impact in the community and to bond with residents remain in the community longer than the average. Emotional and intellectual support through continuing medical education activities also strengthens commitment.

MEDICC Review: What partnerships have proved essential or worked better to help you achieve your goals of social accountability?

Jusie L.J. Siega-Sur (SHS): Key partnerships are with target communities and Local Government Units. First, community willingness to support scholars though training enhances commitment to service on both sides. Secondly, partners' willingness to create positions to absorb scholars upon completion of training and return to the community are essential in deploying graduates to areas where they are most needed. 
The Department of Health (DOH) was the school's major partner in planning, recruitment of students, program implementation, and deployment of graduates. The partnership allowed more focused planning and recruitment of scholars as the $\mathrm{DOH}$ had control over areas of greatest need and availability of positions. DOH also provided data on health system and manpower needs essential for design and continuous updating of the curriculum. $\mathrm{DOH}$, their facilities, and the communities served are training laboratories for the students.

The fact that $\mathrm{DOH}$ supplies facilities and personnel to serve as lecturers and preceptors also contributes to training cost-effectiveness. Similarly, partnering with NGOs allowed the school to augment government resources for scholarships, faculty, and institutional development.

We are also inspired by our partnership with THEnet that brings together other health professional schools sharing similar values and commitment to social accountability.

Paul Worley (Flinders): Partnerships with all levels of government have been crucial for us. Encouraging leadership from clinicians working in underserved communities is vital to implementing our curricular approaches. In addition, gaining inspiration and knowhow from partner medical schools in THEnet has been a strong motivational force in our school.

Roger Strasser (NOSM): The most critically important partnership is with the communities of Northern Ontario. NOSM has Local NOSM Groups (LNGs) in 14 communities across Northern Ontario. The members of LNGs are health service, education and civic leaders, including local government, as well as local NOSM faculty members (physicians and other health professionals) in each community. Each LNG provides the mechanism for NOSM to be a part of the community and the community a part of NOSM.

Juan Carrizo (ELAM): The political will and support shown by our government have proven essential, President Fidel Castro providing not only the original idea for the school-founded even in very difficult economic times for Cuba—but also personal leadership. Second, the medical universities in each province where ELAM students are integrated for their clinical training alongside Cuban students. As you may know, students spend three years at our central campus in Havana-one for bridging courses and Spanish language; and two for basic sciences. Afterwards, they fan out to all the provincial medical schools for their four clinical years.

Which brings me to our most important partnership: with the students themselves. They are the driving force behind the school. They are from 106 countries throughout the Americas, Africa, Asia and the Pacific islands, representing over 100 ethnic groups; half are young women; and three-fourths come from marginalized and disadvantaged communities. They are smart and socially committed, and they make a tremendous effort to become the kind of doctors and leaders their communities need. They also become very united in their diversity at ELAM, where they study in a multicultural setting and learn respect for each other and each other's life experiences and cultures. Such diversity is one of the school's greatest strengths.

At ELAM, there is a Student Council, composed of students from every country, which analyzes the school's directions, formulates joint community projects, and basically discusses all issues related to their life at ELAM to provide us with recommendations. Having the students well organized is a tremendous benefit.

MEDICC Review: If you were to give advice to a dean and trustees establishing a new medical school which they intend to be socially accountable-what would you say? What are the key ingredients to success?

Khaya Mfenyana (WSU): The key ingredients to success are multifold: 1) health and social needs of rural and underserved communities should guide education, research and service provision; 2) special efforts must be made to recruit students from rural and underserved communities; 3) learning and research should be integrated in service delivery and embedded within the health system; 4) most of the learning should take place in primary and secondary health care settings, where the needs are and where most of the students will work after completing their studies, rather than predominantly in tertiary hospitals; 5) the curriculum should integrate basic and clinical sciences with population health and social sciences; 6) early clinical contact and integrated longitudinal clinical community clerkships should be introduced; 7) community engagement should be a facultywide program, rather than just the responsibility of family medicine and public health, meaning that faculty from all disciplines should teach in the community, in addition to local clinicians and community members; 8) interprofessional learning should be introduced in community learning; 9) there should be appropriate academic support that includes teaching and learning facilities, accommodation for students and staff, transport for students, and appropriate network facilities. Finally, there should be a strong partnership between the university, policy makers, health service managers, health service providers, and communities themselves.

Paul Worley (Flinders): It is important that the dean has lived it him or herself-personal experience and integrity are important in the difficult debates that will ensue. It is crucial to understand the academic basis of socially accountable medical education to give credibility to the proposals. This can be learned through both the literature and by visiting exemplary schools.

Opposition is inevitable. The strength of community partnerships will be vital in working to turn this opposition into support. Recruiting staff who share the values of social accountability is also important, so that the culture of the organization is cohesive and aligned.

Roger Strasser (NOSM): Start by asking community members what sort of doctors are needed to meet the needs of the people and communities the school has a mandate to serve. The response should then guide curriculum development, program design, and the organizational structures established. One key ingredient for success is to develop interdependent partnerships with communities in the school's region, so they are actively involved in all aspects of the medical school.

Cristobal Fortunato (ADZU): The dean must have strength of character and an iron will to succeed. Initiating a socially accountable medical school is difficult in the current medical environment. Those who take this path must be totally prepared to face the criticisms that come from all sectors of society, most especially the medical profession. They will face skepticism even from the people they wish to serve. Therefore, they must have a strong 
mission and vision, an excellent plan and faculty absolutely dedicated to the goals of the school.

Juan Carrizo (ELAM): Clarity of purpose and political will to confront the difficulties in the road ahead are of course essential. Plus having faculty who provide living examples to their students of what it means to be a socially accountable physician—who are models of sensitivity, solidarity, and humanist medicine, and who see people as patients and not clients.
Beyond that, however, I would say the most important lesson we have learned is to select well and believe in our students: they are the ones who are going to change the way medicine is practiced, and whose commitment will lead them to partner with communities and other health workers to see that the right to health becomes a reality. -1 -

1. World Health Organization. Reorienting medical education and medical practice for health for all. World Health Assembly Resolution WHA48.8. Geneva, World Health Organization. 1995 May 12. 2p.

Table 1: Socially Accountable Medical Schools: THEnet

\begin{tabular}{|c|c|c|c|}
\hline School & Location & $\begin{array}{c}\text { Year } \\
\text { Founded }\end{array}$ & Program \\
\hline $\begin{array}{l}\text { Flinders University School } \\
\text { of Medicine } \\
\text { http://som.flinders.edu.au }\end{array}$ & $\begin{array}{l}\text { Australia } \\
\text { University campus in } \\
\text { Adelaide, Australia; rural } \\
\text { and remote programs } \\
\text { based in the Northern } \\
\text { Territory, Victoria, and } \\
\text { South Australia }\end{array}$ & 1975 & $\begin{array}{l}\text { Four-year graduate MD program; } \\
\text { parallel Rural Community } \\
\text { Curriculum (PRCC) introduced in } \\
\text { 1997; Northern Territory Clinical } \\
\text { School (NTCS) created in } 1998\end{array}$ \\
\hline
\end{tabular}

University of the Philippines

Manila - School of Health

Sciences

The Philippines

Palo, Leyte

http://www.upm.edu.ph/upmsite /degree/healthsciences.html

Walter Sisulu University Faculty of Health Sciences

South Africa

Mthatha, Eastern Cape

Province

Multi-level entry stepladder curriculum; graduates prepared for many levels of health care provision; communities partner with school in selection and training of students

Six-year undergraduate medical education program; problem-based learning; early clinical exposure in primary and secondary health care in years $4-6$, and in rural settings in years $1-3$ plus 6 weeks in year 4

Four-year graduate MD training, about 50\% community-based;

Ateneo de Zamboanga University School of Medicine

The Philippines

Zamboanga City, Mindanao

http://som.adzy.edu.ph

Latin American Medical School (Escuela Latinoamericana de
Cuba

Havana and provincial medical schools Medicina, ELAM)

1999

http://www.elacm.sld.cu 5th-year Master's in Public Health (MPH); Master's in Health Professions Education also offered

\section{Six-year undergraduate MD} program; 2 years basic sciences, then 4 years clinical rotations; community-based clinical settings emphasized in all years, hospital rotations included; some students spend year 6 in a supervised internship in their home countries

Six-year undergraduate MD program including 20 weeks clinical training in rural and
Australia of Medicine and Dentistry. http://www.jcu.edu.au/medicine Townsville, Northern Australia

Canada

Northern Ontario School of Medicine

Thunder Bay and Sudbury, http://www.normed.ca
Ontario Province isolated settings; years 1-3 largely university based; years 4-6 in health care facilities

\section{Four-year graduate MD program} with 4- and 8-week sessions in respectively: year 3 entirely based in a rural family practice setting

\section{Students}

30 students per year currently in PRCC (entire year 3 in supervised rural practice) and 8 students per year in NTCS 6-month remote clinical attachment

Graduates to date: 100 from PRCC and NTCS combined

Current enrollment: 232 (all levels), 57 (medical program)

Average intake per year: 60 (first level-midwifery), 15 (medical program)

Graduates to date: 125 in medicine; $>1400$ midwives; >650 nurses

Current enrollment: 507

Current intake: 100 new students annually

Graduates to date: 1012

Current enrollment: approximately 125

Graduates to date: 271

\section{Current enrollment: $20,362^{*}$}

Graduates to date: 8594

Current enrollment: 930

Graduates to date: 450

Current enrollment: 64 in each year; first MD graduates in 2009, as well as first 30 family medicine residents Graduates to date: 107

*Includes an additional 10,000 international students incorporated into the ELAM program for the last two academic years, formerly in other medical education programs in Cuba, resulting in near doubling of students' countries of origin.

Source: THEnet, Brussels, Belgium 